\title{
Variable Voltage Control of Three-Phase Induction Motor for Energy Saving
}

\author{
Basem Elhady $^{1}$,Mohamed M. Ismail ${ }^{2}$, Ahmed F. Bendary ${ }^{2}$ \\ ${ }^{I}$ Department of Electrical Eng., Suez Canal University, Cairo, Egypt. \\ ${ }^{2}$ Department of Electrical Eng., Helwan University, Cairo, Egypt.

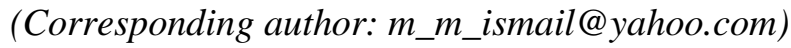

\begin{abstract}
Energy saving is considered one of the important factors for industrial and commercial applications. Induction motors are the mostly preferred motor in the industry due to their reliability, robustness, price and rugged construction. The largest percentage of consumed energy in the industrial section is consumed by induction motors. So, Energy conservation in induction motor drive leads to reduction in power consumption and electricity cost. This paper studies an energy saving technique for squirrel cage induction motor. The energy saving is achieved by controlling the voltage applied to the stator winding using the three phase AC voltage controller. The simulation verifications were performed using MATLAB/Simulink. The results show that the proposed scheme gives rise to considerable energy savings.
\end{abstract}

Keywords: Induction motor drive; energy saving; reducing voltage; motor losses.

\section{Introduction}

Motor drive systems can consume over $50 \%$ of Energy consumption in the commercial field. These systems can consume over $75 \%$ of the electricity in the industry. Also motor drives are popularly used in air conditioning, fans, pumps, compressors, elevators, and industrial drives. These motor drives include induction motor drives, DC motor drives, synchronous motor drives, as well as other motor drives. Among these drives, induction motor drives are the most prevalent in real applications [1].

Induction motors are widely used in many fields of industrial production systems and there is a strong demand for their reliable and safe operation.

In the industry, squirrel cage induction motor drives are the major power consuming devices and they mostly preferred for industrial applications. So, energy conservation in this squirrel cage induction motor drive leads to reduction in electricity cost of the industry. Many energy conservation techniques are available for induction motor drives they are classified into online and offline [2-3]. The online method includes voltage balance, proper cooling, flux optimization, APFC and Losses at switches, and the offline method includes suitable Hp rating selection, suitable capacitance rating selection, selecting good quality coils, and selecting good quality core.

In offline method, the energy conservation is achieved by replacing unwanted higher rating motor with suitable rating motor for driving the load. This will reduce the total losses and cost of the motor. In online method, the energy conservation is done by flux optimization in induction motors. Reactive power compensation in three phase squirrel cage induction motor is presented in Reference [4].

Energy saving is essential nowadays because of growing demand for electrical power everywhere the world. Constant speed operation of induction motor is used in applications such as spinning drive-in textile industry, mine hoist load, drill presses and wood saw [5-6]. There has been a mounting global concern over energy consumption and high energy efficiency has become one of the most factor in the development of the products that consume electrical energy. The decreasing of both the efficiency and the power factor of the motors is the results of these applications of the induction motors because these applications are variable-load, in these applications the motor can have low-load operating periods in which the efficiency and power factor can be marked low [7]. Both efficiency and power factor of the motors can be improved significantly in the low load operating period, if the stator winding voltage is properly regulated or can be reduce to proportional the varying of load torque [8].The rated efficiency of an induction motor is high when it operates under the full load. In general, the rated efficiency is larger than $75 \%$. Although the operating efficiency of the induction motor drive system will be low if an induction motor is operating at light loads. So, that the improvement in the energy efficiency of induction motor drives refers to huge energy saving [1].

\section{Analysis of three phase induction motor:}

Fig. 1 shows the equivalent circuit of a three-phase induction motor. Using reference frame theory, a 
detailed analysis for induction machine has been carried out. The variation of the torque and currents with the variation of input voltage can easily obtained [8]. The induction motor's input power $\mathrm{P}_{1}$ is consumed in the stator winding resistance and becomes the copper consumption $\mathrm{P}_{\mathrm{Cu} 1}$; another part is consumed on the stator core and becomes the iron consumption $\mathrm{P}_{\mathrm{Fe}}$. The power transmitted to the rotor via an air gap is the electromagnetic power $\mathrm{P}_{\mathrm{em}}$ [9], thus:

$\mathrm{P}_{\mathrm{em}}=\mathrm{P}_{1}-\mathrm{P}_{\mathrm{cu} 1}-\mathrm{P}_{\mathrm{fe}}$.

where:

Electromagnetic power $\mathrm{Pem}=\frac{3 I_{2}{ }^{2} \widehat{R 2}}{S}$

Input power $\mathrm{P}_{1}=3 V_{1} I_{1} \cos \emptyset$

Copper consumption $\mathrm{P}_{\text {cul }}=3 I_{1}{ }^{2} R_{1}$

Iron consumption $\mathrm{P}_{\mathrm{fe}}=3 I_{m}{ }^{2} R_{m}$

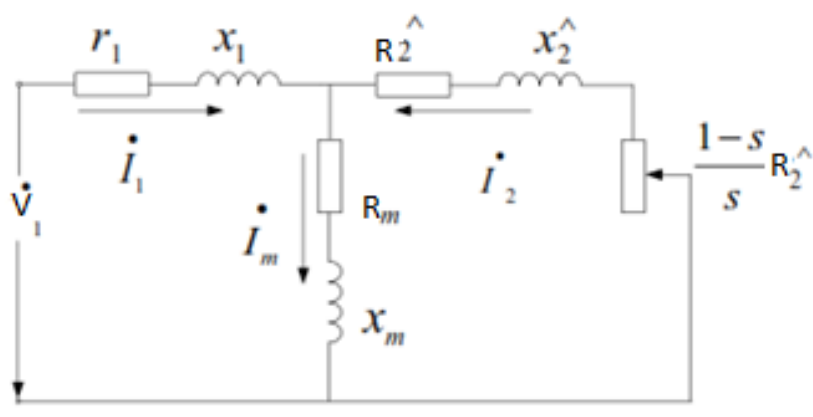

Figure1- Equivalent circuit of three-phase induction motor [9]

The power flow chart is shown in Figure 2 for threephase induction motor. From Fig.2, one part of $\mathrm{P}_{\mathrm{em}}$ is consumed on the rotor winding resistance and becomes the rotor copper

Consumption $\mathrm{P}_{\mathrm{Cu} 1}$. Most of the rest is transmitted to the rotor shaft and converted into the mechanical power $\mathrm{P}_{\text {mec }}$.

where:

Rotor copper consumption

$P_{c u 2}=3 I_{2}{ }^{2} \widehat{R 2}$

Motor mechanical power

$P_{\text {mec }}=(1-s) P_{\text {em }}$

The final mechanical power $\mathrm{P} 2$ from the rotor shaft is got from $\mathrm{P}_{\mathrm{mec}}$ by deducting the rotor shaft's mechanical loss $\mathrm{P}_{\mathrm{m} 1}$ caused by friction and air resistance alike and the stray loss $\mathrm{P}_{\Delta}$ caused by harmonic waves, where the mechanical loss and stray loss are related with the motor's structure, accounting for about $20 \%$ of the motor's total losses whose major losses are from the copper and iron.

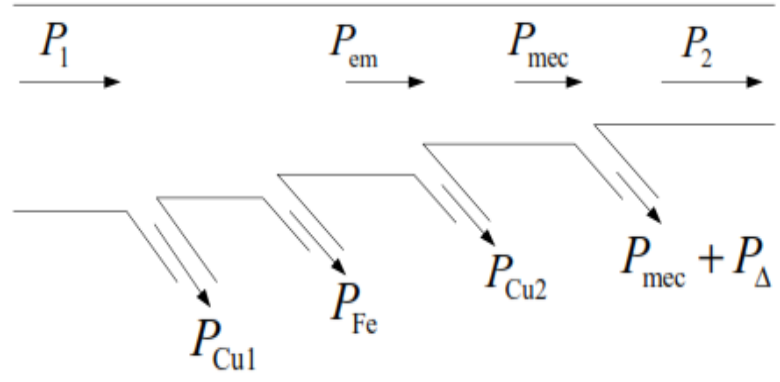

Figure 2- Power flow chart

\subsection{Types of losses in three phase induction motors}

There are two types of losses occur in induction motors. The efficiency of a motor is determined by intrinsic losses that can be reduced only by changes in motor design. Intrinsic losses are of two types: fixed losses, and variable losses [10].

\subsubsection{Fixed losses}

It independent of motor load consist of magnetic core losses and friction and windage losses. Magnetic core losses (sometimes called iron losses) which is the combination of eddy current and hysteresis losses in the stator. Friction and windage losses are caused by friction in the bearings of the motor and aerodynamic losses attached with the ventilation fan and other rotating parts [10]. In small-size induction motors, core losses generated constitute a significant part of total losses in such machines [8].

\subsubsection{Variable losses}

It dependent on load consist of resistance losses in the stator and in the rotor and multifold stray losses. Resistances to current flow in the stator and rotor result in heat generation that is proportional to the resistance of the material and the square of the current (I2 R). Stray losses originate from a variety of sources and are difficult to either measure directly or to calculate but are generally proportional to the square of the rotor current [10]. On an average, 60100 times is the ratio between the energy consumed by an induction motor during its life cycle to the initial cost of the motor. Important factor in the case of energy saving motors is accurate determination of these losses [11].

\subsubsection{Core loss}

Core loss represents energy required to magnetize the core material (hysteresis) and includes losses due to generation of eddy currents that flow in the core. Core losses are those found in the stator-rotor magnetic steel and are due to hysteresis effect and eddy current effect during magnetization of the core material [10].Mechanical (windage and friction) losses occur due to bearing friction and air resistance. Both core losses and Mechanical losses are independent of motor load. Mechanical losses 
represent about $8-12 \%$ of total losses. The reduction in heat generated by stator and rotor losses allows the use of smaller fan [10].

Stator losses appear as heating due to current flow (I) through the resistance $(\mathrm{R})$ of the stator winding. This is commonly referred to as an $\mathrm{I}^{2} \mathrm{R}$ loss. These losses are major losses and typically account for 55-60\% of the total losses. $\mathrm{I}^{2} \mathrm{R}$ losses are heating losses resulting from current passing through stator and rotor conductors [10].Rotor losses appear as $I^{2} R$ heating in the rotor winding. Rotor losses can be reduced by increasing the size of the conductive bars and end rings to produce lower rotor losses [10].Stray load losses are the result of leakage fluxes (I) through the resistance $(\mathrm{R})$ of the stator winding and appear only when the motor is operating at under load. These losses vary according to square of the load current and are caused by leakage flux induced by load currents in the laminations and account for $4-5 \%$ of total losses [10].

\section{Modelling of Induction Motor}

In this Section, the simulation model implemented in MATLAB environment for induction motor will be analyzed using electrical and three phase voltage control models, which interact as diagrammed in Fig. (3). the block diagram of the electrical model for the induction motor is schematically represented. In the electrical model, the voltage" $\mathrm{V}$ " and the torque " $\mathrm{t}$ " determine the stator and rotor current. The summation of all torques acting on the motor shaft comprises the mechanical model. Here, the driving torque developed by the motor is resisted by the load torque and the moment of inertia of all the rotating elements, each of them is slip dependent. The thermal model depends on the equation for heat rise due to current flowing in a conductor determined by the feedback control, and the rotor slip and according to the ultimate protection criteria [5-7].

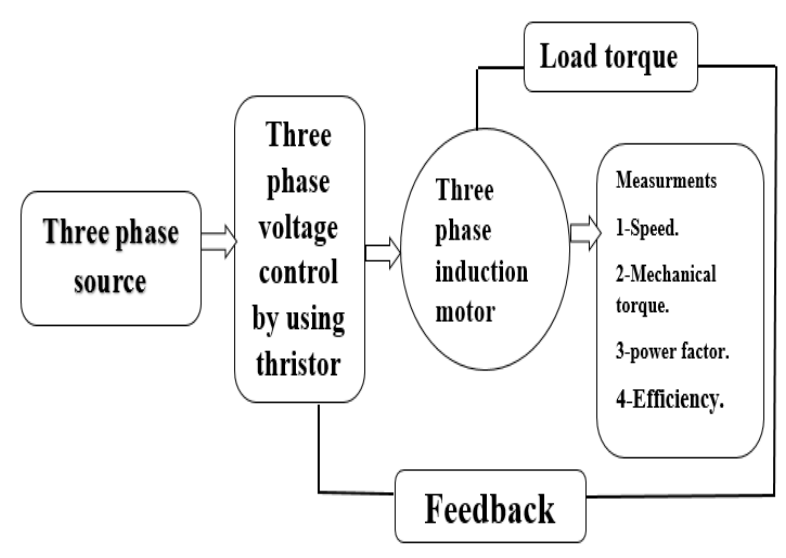

Figure 3- Block diagram of the electrical model for the induction motor

\subsection{Estimation load torque of the motor:}

Three steps are used to estimate efficiency and load. First, use input power, line current or slip measurements to identify the load imposed on the motor. Second, obtain a motor part-load efficiency value. Finally, obtain a modified load using the power measurement at the motor terminals and the part load efficiency value [12].

A- Input Power Measurements

The motors load can be quantified by comparing the measured input power under load to the power required when the motor operates at rated capacity. The relationship is shown in equation (8):

Load $=\frac{P_{i}}{P_{\text {ir }}} * 100 \%$

With load the output power as a percentage of rated power, $\mathrm{P}_{\mathrm{i}}$, the measured three phase power in $\mathrm{KW}$, and $\mathrm{P}_{\mathrm{ir}}$, the input power at full rated load in $\mathrm{KW}$.

B-Line Current Measurements

The current load estimation method is recommended when only amperage measurements are available. In the low load region, current measurements are no longer a useful indicator of load. Thus, root mean square current measurements should always be corrected for voltage.

C-The Slip Method

The slip method is recommended when only motor operating speed measurements are available. The motor load can be estimated with slip measurements as shown in equation (9):

$\operatorname{Load}=\frac{I}{I_{r}} * \frac{V}{V_{r}} * 100 \%$

When a load is connected, the output power is a percentage of rated power, I is the RMS current (mean of 3 phases), $I_{r}$ is the rated current, $V$ is the RMS voltage, (mean line to line voltage of the 3 phases), and $\mathrm{V}_{\mathrm{r}}$ is the rated voltage.

3.2. Block diagram of energy saving device in induction motor

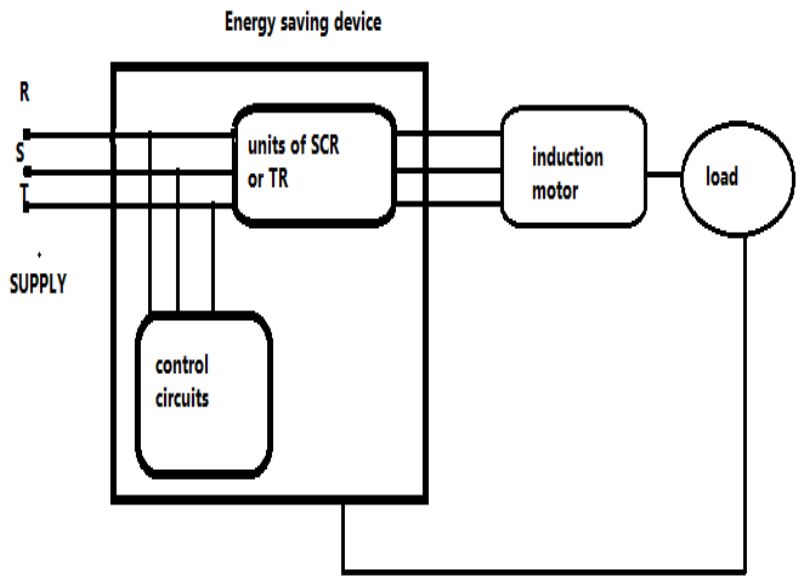

Figure 4-Energy saving device block diagram. 
Fig. 4 shows the device of energy saving which connect between the source and the motor where the device contains units' group such as TR or SCR to reduce the voltage and control circuits to ignition this units, as it should be influenced the ignition with the current and voltage of the load. The device also includes on microprocessor for programming plus ignition according to the required load.

In ref. [13], a method of improving efficient energy usage in induction motor drive system when operated under high temperature condition has been presented through confining the drive signal to the prospective domain of that compensated by operating temperature range, an optimum point of driving performance and energy efficiency will be met for the given load torque and speed command.In ref. [14], A solution of the national economic problem of saving electricity during the operation of three-phase asynchronous electric motors used to drive working machines of technological lines has been presented.In ref. [15], many variables and constraints are involved in design problem which considered as a nonlinear constraint optimization problem, the cost of yearly energy losses is considered as objective function and it is optimized to save energy and money as well.

\section{Simulation results}

The parameters of the system under study are given in the appendix. MATLAB/SIMULINK software is used to perform the simulation using power system block sets with a simulation time of 5 seconds as shown in the below figures.

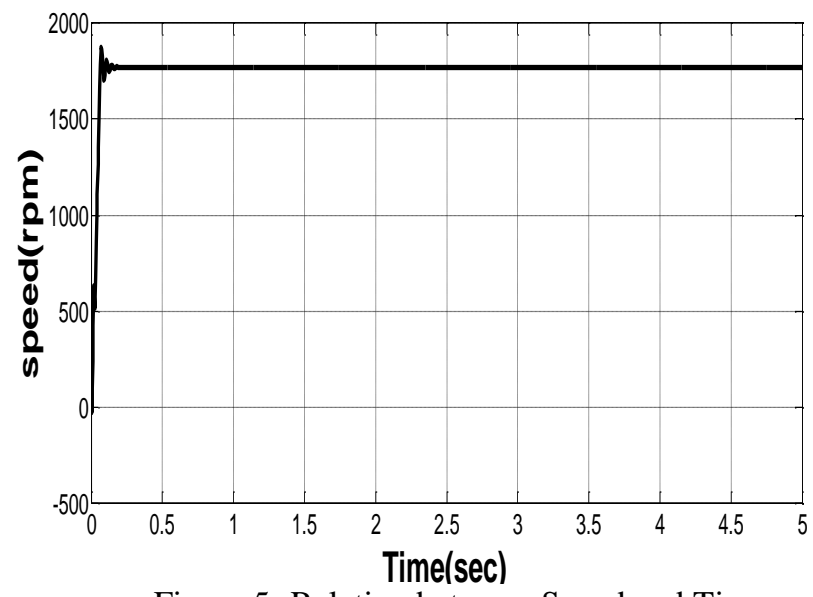

Figure 5- Relation between Speed and Time

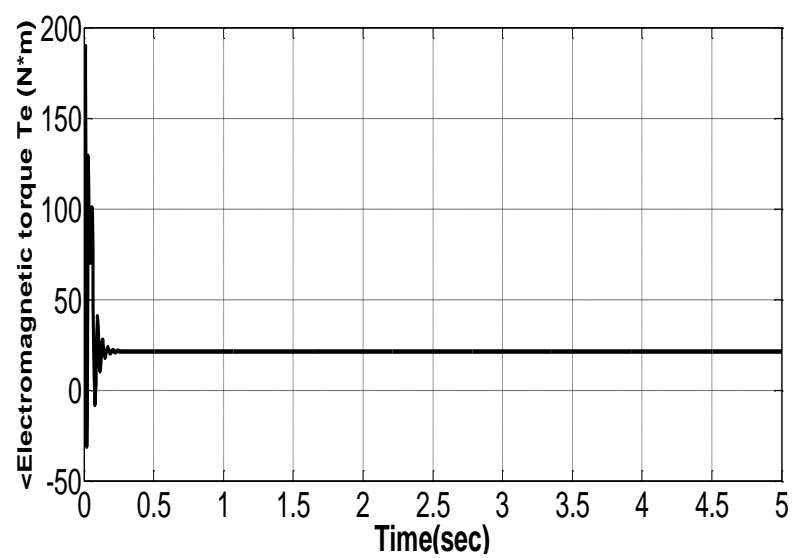

Figure 6- Relation between load torque and time

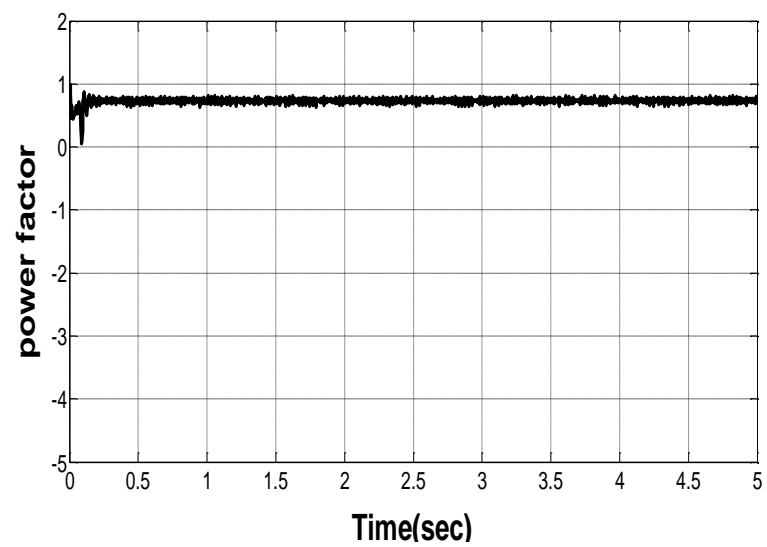

Figure 7- Relation between P.F. and Time

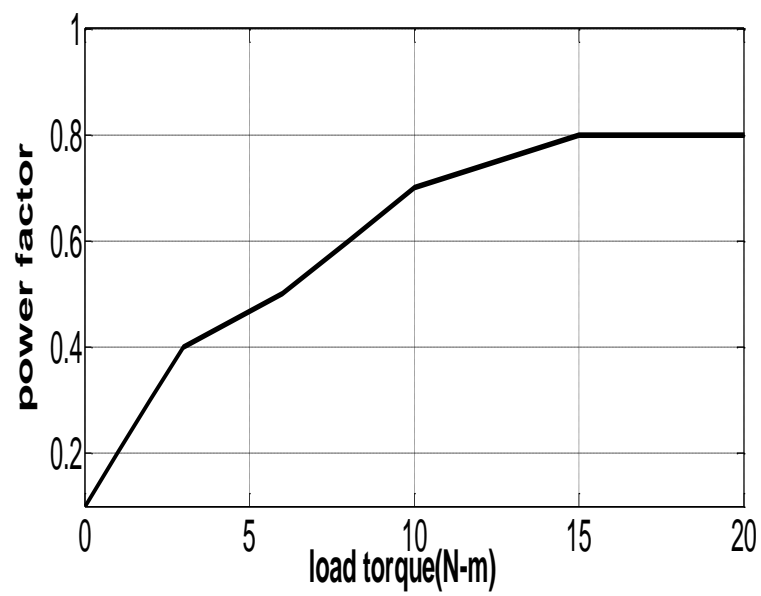

Figure8- Relation between load torque and P.F. 
Table 1- Optimal voltages and currents of variant load torques at nominal frequency

\begin{tabular}{|c|c|c|}
\hline $\mathrm{V}_{0}($ Voltage $)$ & $\mathrm{I}_{\mathrm{o}}($ Ampere $)$ & $\mathrm{T}$ (Newton. Meter) \\
\hline 440 & 6.6 & 20.3 \\
\hline 360 & 6.1 & 15 \\
\hline 320 & 4.8 & 10 \\
\hline 290 & 4.2 & 8 \\
\hline 240 & 3.8 & 6 \\
\hline 150 & 3.4 & 3 \\
\hline 120 & 3.2 & 2 \\
\hline 110 & 2.4 & 1 \\
\hline
\end{tabular}

Table 2- The efficiency, power factor and losses without saving (At voltage $=460$ volt)

\begin{tabular}{|c|c|c|c|c|c|c|}
\hline Pin & Pout & Loss & $\begin{array}{c}\text { Power } \\
\text { factor }\end{array}$ & $\begin{array}{c}\text { Efficiency } \\
(\eta)\end{array}$ & $\begin{array}{c}\mathrm{T}_{\mathrm{L}} \\
(\mathrm{N} . \mathrm{M})\end{array}$ & Load (\%) \\
\hline 4227 & 3738 & 539 & 0.82 & 0.87 & 20.3 & 100 \\
\hline 3397 & 2797 & 618 & 0.79 & 0.81 & 15 & 75 \\
\hline 2517 & 1863 & 654 & 0.69 & 0.74 & 10 & 50 \\
\hline 2122 & 1494 & 628 & 0.64 & 0.70 & 8 & 40 \\
\hline 1623 & 1123 & 500 & 0.54 & 0.96 & 6 & 30 \\
\hline 1161 & 563 & 598 & 0.4 & 0.48 & 3 & 15 \\
\hline 894 & 376 & 518 & 0.3 & 0.40 & 2 & 10 \\
\hline 501.8 & 188 & 314 & 0.2 & 0.30 & 1 & 5 \\
\hline 281.3 & 0 & 281.3 & 0.1 & 0 & 0 & 0 \\
\hline
\end{tabular}

Table 3 Comparison the values of efficiency, power factor and losses with Energy saving (At voltage $=460$ Volt $)$

\begin{tabular}{|c|c|c|c|c|c|c|c|}
\hline Pin & Pout & Loss & $\begin{array}{c}\text { Power } \\
\text { factor }\end{array}$ & $\begin{array}{c}\text { Efficiency } \\
(\eta)\end{array}$ & $\begin{array}{c}\text { Voltage } \\
(\text { Volt })\end{array}$ & $\begin{array}{c}\text { TL } \\
(\mathrm{N} . \mathrm{M})\end{array}$ & Load (\%) \\
\hline 4252 & 3730 & 522 & 0.84 & 0.88 & 440 & 20.3 & 100 \\
\hline 3212 & 2746 & 466 & 0.87 & 0.85 & 360 & 15 & 75 \\
\hline 2209 & 1838 & 371 & 0.85 & 0.83 & 320 & 10 & 50 \\
\hline 1815 & 1471 & 344 & 0.85 & 0.81 & 290 & 8 & 40 \\
\hline 1408 & 1099 & 309 & 0.86 & 0.78 & 240 & 6 & 30 \\
\hline 801 & 541 & 260 & 0.89 & 0.67 & 150 & 3 & 15 \\
\hline 614.4 & 357.2 & 257.2 & 0.9 & 0.58 & 120 & 2 & 10 \\
\hline 624.3 & 181 & 243 & 0.9 & 0.4 & 110 & 1 & 5 \\
\hline 223.1 & 0 & 223.1 & 0.75 & 0 & 100 & 0 & 0 \\
\hline
\end{tabular}




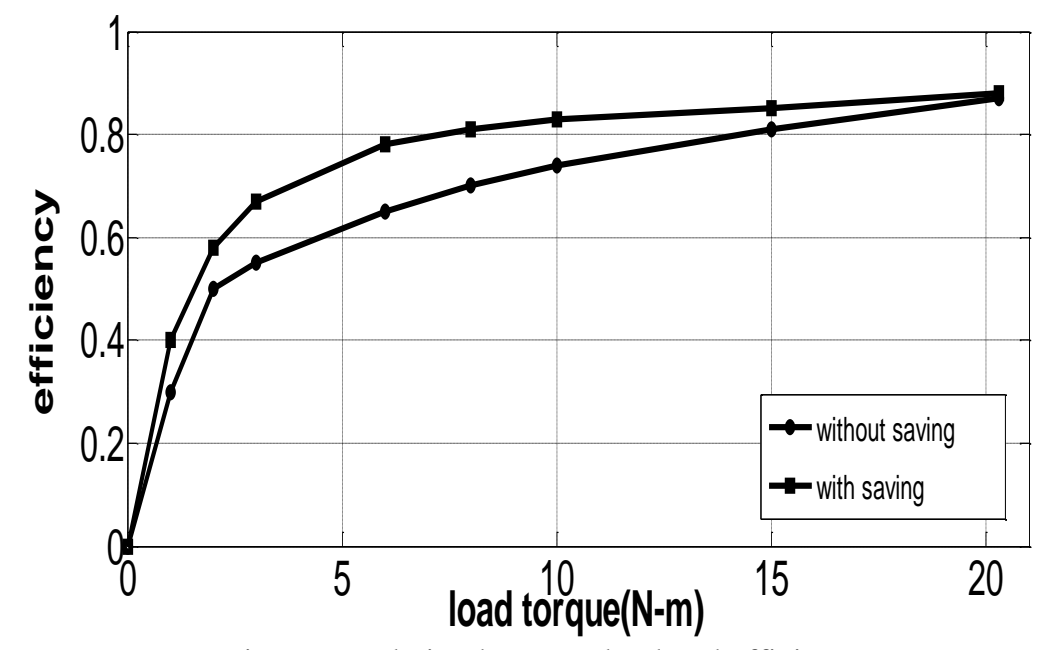

Figure9- Relation between load and efficiency

Figure (5) shows the output signal using MATLAB Simulink software for Speed with a simulation time of 5 seconds, figure (6) shows the output signal using MATLAB Simulink software for load torque and Time for the same time period, figure (7) shows the Relation between load P.F. and Time for the same time period, figure (8) represents the load torque and P.F output relationship, figure (9) shows the operating motor with energy saving where observe or recognize the values of efficiency improve although the value of load torque decrease.Table1 shows the relationship between the stator current and stator voltage at different load torques can be obtained by using MATLAB where, the value of current and voltage decreased when reduce the value of torque. The maximum efficiency of induction motor can be achieved when operates at full load but when reduce the load torque without reduce stator voltage the efficiency, stator current, power factor, input power and output power are decreased but losses increase this is meaning the motor operate without energy saving this is show in Table 2 .

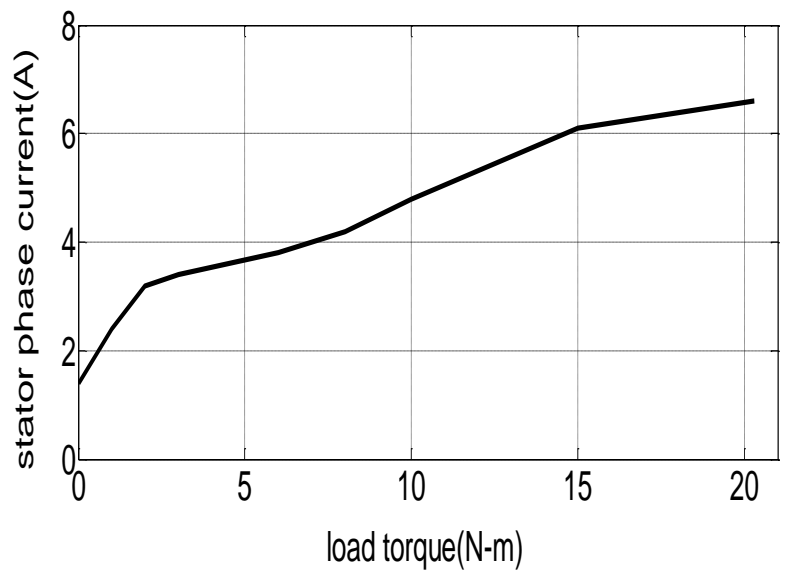

Figure 10- Relation between load torque and current

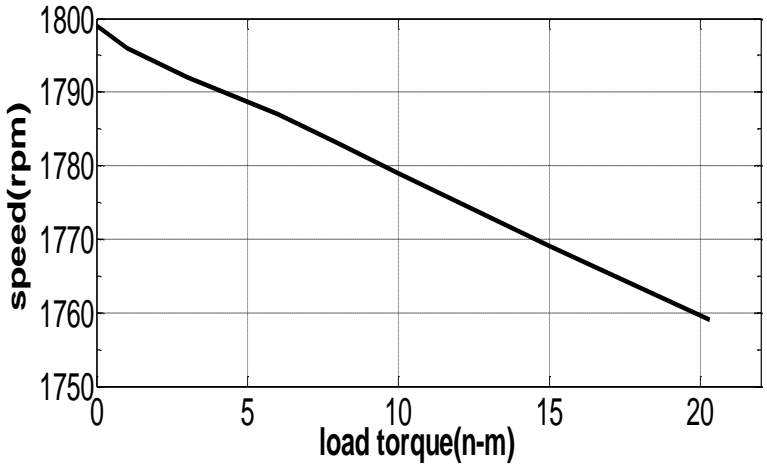

Figure 11- Relation between load torque and speed

\section{Conclusions}

This paper presents energy saving technique for squirrel cage induction motor. The energy saving is achieved by controlling the voltage applied to the stator winding using the three phase AC voltage controller. The presented output results show different ways of energy conservation in induction motor drive. The energy saving done in the presented model through make higher energy conservation which achieved by using such methods as selecting good quality cores and coils, flux optimization, automatic power factor correction, selecting suitable fixed capacitor for reactive power compensation, voltage balance and selecting suitable rating of motor corresponding to load or smaller energy conservation is achieved in methods such as reducing losses at power electronic switches and proper cooling. The output results analysis shows the validity of the model controller used and its high performance for the efficiency and losses power saving. 


\section{References}

[1] X.D.Xue and K.W.E. Cheng, " An energysaving scheme of variable voltage control for Three- phase induction motor drive systems, " The Hong Kong polytechnic university, china, 2006,PP.241-243.

[2] Ali M Bazzi and Phili T Krein, " Review of Methods for real time loss minimization in induction machines, " IEEE transactions on industry applications, vol. 46, No. 6, Nov/Dec,2010, pp. 2319-2328.

[3] M. Nasir Uddin and Sang woo Nam, "New online loss- minimization Based control of an induction motor drive, " IEEE Transactions on power electronics, vol. 23, No. 2, March 2008, pp. 926-933.

[4] Tjahjono, Gunadi \& Ray, Fransiskus \& Fahmi, Ichsan \& Tamal, Crispinus \& Modok, Renold \& Setiawaty, Tetty, "Reactive power compensation in squirrel cage rotor type of three-phase induction motors". IOP Conference Series: Materials Science and Engineering.830.032035. 10,2020, pp.1-8. doi:10.1088/1757-899X/830/3/032035.

[5] Gajendra singh and N.K. sharma, " Energy efficient industrial motors, " International Journal of engineering science and technology, vol. 12, 2010, pp.7904-7913

[6] C. Thanga Raj, P. Srivastava and Pramod Agarwal, " Energy efficient control of three phase induction motor -Areview, " International Journal of computer and electrical engineering, No. 1, April 2009,pp.61-70.

[7] F. Ferreira and A. de Almeida, " Methode for infield evaluation of the stator winding connection of three phase induction motors to maximum efficiency and power factor, " IEEE Transactions. Energy conversion, vol. 21, No. 2, Jun, 2006, , pp. 370-379.

[8] Mohamed A. Enany, " Energy saving of ac voltage controller fed induction motor drives using mat lab/Simulink, " Faculty of Engineering, Zagazig university, Zagazig, Egypt, International Journal of electrical engineering, vol. 6, No. 2, 2013, pp. 123-136,

[9] Zhou Jing-hua, Chen Cheng, Zhang Xiao-wei and Chen Ya-ai, "Reducing voltage energysaving control method of induction motor," 2013 International Conference on Electrical Machines and Systems (ICEMS), 2013, pp. 2159-2162 doi: 10.1109/ICEMS.2013.6713202.

[10] R. Saidur, " A review on electrical motors energy use and energy savings," Department of mechanical engineering, university of Malaya, vol. 14, 2010,pp. 877-898.
[11] Krzysztof Komeza, and Maria Dems, " FiniteElement and Analytical Calculations of NoLoad Core Losses in Energy-Saving Induction Motors," IEEE Transactions on Industrial Electronics, vol. 59, no. 7, July 2012, pp. 29342946.

[12] S. Corina, E. Romero and L. F. Mantilla, " How the efficiency of induction motor is measured, " Department of electrical engineering and energy, E. T. S. I. I. Y T. Universidad Cantabria, vol.6, No. 6,2008,pp.530-534.

[13] N. Jirasuwankul “ Simulation of Energy Efficiency Improvement in Induction Motor Drive by Fuzzy Logic Based Temperature Compensation", Engineering Energy Procedia, Volume 107, February 2017, pp. 291-296.

[14] O. Vovk, S. Kvitka, +1 author O. Strebkov "Energy-Saving Control of Asynchronous Electric Motors for Driving Working Machines" Computer Science,2019,pp.415-423.

[15] PradipKumarSadhu,RajuBasak,AmarnathSanyal and Pritish Kumar Ghosh "Energy efficient design of three phase induction motor by water cyclealgorithm" Ain Shams Engineering Journal Volume 11, Issue 4, December 2020, pp. 11391147. 